\title{
Reflections on COVID-19 and the future of education and learning
}

\author{
Simona Popa ${ }^{1}$
}

Published online: 29 September 2020

(C) UNESCO IBE 2020

This special issue of Prospects comes out during extraordinary times, which have changed the educational world almost beyond recognition. The whole education scene has started to look surreal: Schools have been shutting their doors, and parents and caregivers have been scrambling to "homeschool" their children and to look for ways to keep them engaged. Wherever possible, a stronger engagement with remote learning has taken place.

\section{Uninterrupted learning during a global learning crisis}

Under such shaky circumstances, retaining a sense of normality for learners and their teachers has been crucial. Given this unprecedented closure of learning institutions, one of the most pressing tasks facing educators is to ensure that students' learning is uninterrupted.

Making sure that learning never stops is imperative (UNESCO 2020). Yet, focusing on the never-stopping part alone, as if it does not affect everything else about the purpose and the value of schooling, is rather narrow and might give the debate an air of deceptive simplicity. We also need to make sure that learning—quality learning—actually happens. The task is all the more urgent and complicated as education itself is already going through its own massive crisis - the global learning crisis — which is being amplified by the COVID19 pandemic.

\section{Unfinished business while imagining a better world}

Sadly, we had zero foresight of the many changes the pandemic would bring to education and learning. And we hardly have any sense of the scale and range of what is to come. Even so, there has been no shortage of speculation about what the COVID-19 pandemic

Simona Popa

ibe.prospects@unesco.org

1 UNESCO International Bureau of Education (IBE), P.O. Box 199, 1211 Geneva 20, Switzerland 
will do to change education and learning as we know them. Furthermore, the discussion has been driven in wildly different directions by different notions of what sort of knowledge, of what sort of reality, to what sort of end, they are supposed to produce.

We talk about what we owe the future, but what about our obligations to the present? We owe it to the 617 million children and adolescents who are not proficient in either reading or mathematics (UIS 2017) to have the chance to gain foundational skills that stem from literacy and numeracy. And we owe it to those students to ensure that they are all given equitable learning and equal opportunities. We also owe it to the teachers, to provide them with the necessary tools to translate the goals and objectives of their education systems into learning outcomes.

However, it is not enough to readily acknowledge our duties to our contemporaries or to those who come after us. To understand the complexity of the changes ahead, we need to be acutely conscious of the history of our time in terms of the unmanageable, overwhelming reality of what still needs to be done. Globally, we have been moving backwards rather than forwards (World Economic Forum 2019), and, five years since the adoption of the UN Sustainable Development Goals, tangible progress is still to come. We have not changed the world for the better; rather, as Tony Judt (2012) would have put it, "the world changed obligingly for us".

We also need to be acutely conscious of the history of our time in terms of the unmanageable, overwhelming reality of the COVID-19 pandemic. Without urgent action, the COVID-19 crisis could push half a billion more people into poverty globally (Oxfam 2020). The ILO (2020) estimates that nearly 25 million jobs could be lost globally due to the coronavirus. The crisis will hit the poorest the hardest, entrenching extreme levels of inequality. The economic and social effects of lockdowns, loss of production and business confidence, and global recession will cast a long shadow over education systems (Keith Lewin, in this special issue).

COVID-19 presents education and learning with a unique challenge: to further define their nature and purpose against the backdrop of the current, highly volatile context, and to fulfill an important, concretely transformative role with regard to the post-2015 global education agenda.

However, talking about the future of education and learning right now can easily create a quagmire of statements of all sorts, artifices, and self-deceptions. Bit by bit, words like "reimagining", "redefining", "reconceptualizing", "reinventing", or "reorienting" education and learning become part of our lofty academic vocabulary. To be sure, they express a significant degree of discomfort with the current metanarrative, but there is certainly more at stake here than the use of provocative metaphors to unravel bedrock assumptions and to incite further discourse. The exercise of repositioning education and learning or even shifting these paradigms forces us to tackle the issue of their "nature" honestly and represents an important advance that cannot be ignored or easily dismissed. What may on the surface look like an overlying terminology detail is a matter of enormous potential impact and relevance for the future of education and learning.

Thus, I argue that our main task right now is to not still be talking about the things we have not accomplished yet. The most important thing for us to do is to imagine better worlds, while taking action on what we should still be caring about today. Clearly, our modes of thought and action should be brought into harmony with the new objective conditions of the world. However, we need to be rationally aware of what we still need to achieve, and we should be able to act according to that awareness.

Virtually every detail of the current situation serves to remind us that to think and act as though we were living in the past of only a few months ago is at best useless and at worst 
fraught with great risks. We should do more than pick up the pieces and carry on as before. More to the point, we just cannot go on living like this. Urgent action is needed if this situation is not to become another pandemic, threatening the very survival of our world. The audacity of this much-needed action, which is set against the foil of real suffering, can be felt most immediately in its ambition: Can we transform this crisis into a renewing wave? Will it help bring about a better education system, a better society, and a better world?

\section{About the articles in this issue}

Included in this special issue are authors whose names stand out: inspiring thought leaders and bold practitioners who bring to Prospects an astonishing range of knowledge, a commitment to an idea of public good and community, and an intense intellectual and emotional engagement. This engagement is - how else? - political. In what they write, there is always that moral edge, but there is also a call to action. How do they address the pressing issues of the day? How do they address the completely unknown, even if, at times, intensely familiar future?

This issue opens with a superb piece by Sir Ken Robinson: "A Global Reset of Education". Sent to Prospects shortly before his untimely death, it now takes on a whole new meaning. Sir Ken writes that as the world looks to the future and for ways of safely returning to normal, we have a unique opportunity to reset our priorities and redefine what this normal looks like. What type of normal do we want to get back to, and is it the normal that we have left behind us? He believes that it should not be, and that we are at an exceptional moment in time to redirect our course. For education communities, this is a chance to take a close look at aspects of education systems that we have taken for granted for far too long.

Hans d'Orville, former UNESCO Assistant Director-General for Strategic Planning, asks a similar question: What should a "new normal" look like for future generations? How can countries use the innovativeness of the recovery period to "build back better"? His Viewpoint highlights the UNESCO-led Global Education Coalition initiative, which is seeking solutions to support learners and teachers, as well as governments, throughout the recovery process, with a principal focus on inclusion, equity, and gender equality. D'Orville contends that the current crisis is an opportunity for stronger international collaboration, which might provide a better focus and deliver solutions including digital tools. Resilience and adaptability will be crucial for the next generations to navigate through the present pandemic — and any in the future.

In his article, Keith Lewin discusses the fact that COVID-19 is reshaping the debate about education and development. The simple truth, he says, is that no one has a clear idea of how the current pandemic will unravel over anything but the short term. Therefore, he advances ten propositions that will shape policy dialogue and whatever iteration of the Sustainable Development Goals is needed to ensure they remain fit for purpose. Testing these propositions over the coming year will open the door to an evidence-based approach to reconstruction and sustainable development and juxtapose immediate concerns of the present with aspirations for the future.

Michael Fullan reasons that school systems around the world were stagnant before COVID-19 and had been for some time. Therefore, he writes, there was considerable pent-up energy to make changes. COVID-19 has both exposed and exacerbated what was wrong with the system, but it has also provided opportunities to make changes amidst the 
confusion. Change doesn't get more complex than is the case right now, and the complexity becomes more convoluted every day. Change will happen-we just do not know what it will look like. We have "the battle of the decade" on our hands with respect to publiceducation systems.

Yong Zhao suggests that COVID-19 represents an opportunity to rethink education, and that the rethinking should not be about improving schooling but should focus on the what, how, and where of learning. While school closures have prompted innovation and institutional self-examination, the chance of large-scale, long-term changes is largely dependent on how we treat COVID-19 in education. If we treat COVID-19 as a short-term crisis, Zhao warns, then whatever we do to help extend learning when schools are closed will be only temporary.

António Nóvoa and Yara Alvim argue that the debates about the future of education and the need to rethink the school model started long before the pandemic crisis, but that the situation we are experiencing has magnified this need, while also showing that change is possible. The dynamics of transformation and metamorphosis of schools have emerged, reinforcing education as a public and common good. Nóvoa and Alvim clarify the dynamics that redefine the three foundations of the school model: the social contract around education, the organizational structure of the school, and the pedagogy of the lesson.

In his contribution, Robert Arnove writes that the COVID-19 crisis offers a unique chance to imagine more equitable societies and education systems. The pandemic's disproportionate, terrible consequences for health and livelihoods-for individuals, their communities, and even whole societies - underscore institutionalized forms of discrimination rooted in race, ethnicity, class, gender, sexual orientation, age, and abilities. The lessons of COVID-19 compel us to imagine education systems in which students of all ages can thrive, and we need to take meaningful action to bring about that desired future.

Nelly Stromquist argues that COVID-19 and the likely long economic recovery from it are worsening the already low budgets confronting many governments in developing nations. But we should remember that the erosion of the public sector in those countries has been going on for four full decades. The climate of state austerity and the growing privatization of education have brought new priorities for political leaders and parents, leaving issues of social justice, such as the indispensable transformation of the social relations of gender, to be tackled at only superficial levels. While efforts must continue to achieve universal primary and secondary education at the global level for both boys and girls, the concern with access and thus enrollment and completion parity has blinded many governments from seeing the crucial need to examine what is actually learned in school. Stronger concern with curriculum would bring a stronger focus on the formal knowledge conveyed in schools and on the ways in which this knowledge might (or might not) facilitate a substantial change in the social relations of gender.

In their article, Colette Chabbott and Margaret Sinclair claim that COVID-19 once again reveals the inherent weaknesses in relying on classroom-based schooling and ICT to sustain learning, a danger already familiar from earlier disasters, both natural and caused by humans. A lack of textbooks and of guidance for caregivers to support home-based learning limited the effectiveness of efforts to provide continuity of learning. These same elements are the key to preparing better for the next crisis and to keeping SDG Goal 4 on track.

Crain Soudien calls for a more developed understanding and approach to the questions of inequality and education. While much of the current discussion is, correctly, focused on learners' material realities and how COVID-19 is exacerbating inequalities, what is largely overlooked is how the core activity of the education experience-learning-is managed, 
both at the macro-level of the state and at the micro-levels of the individual learner. We now know how complex learning is, and our new knowledge is informed by new understandings of the relationship between the biomedical and the social. Soudien writes that it is necessary to deconstruct and make sense of the complexities of these realities for the quality of the learning experience, both during this crisis and going into the future.

Conrad Hughes reasons that the "industry of modern schooling" leads to surface learning of exaggeratedly voluminous curricula and excessively high-stakes assessments that instrumentalize the pursuit of knowledge. In order to return to a more mindful, authentic, and humanly paced approach, some disruption from the present model is needed. Paradoxically, the COVID-19 pandemic might be the catalyst that will bring this about.

Miguel Ángel Escotet declares that the absence of worldwide social ethics is at the root of our present social, political, and economic crises. More to the point, the current COVID19 pandemic is, in part, a consequence of insufficient scientific research, inappropriate education systems, and globally fragile health structures and human services.

Radhika Iyengar asserts that COVID-19 has disrupted education for millions of children across the globe. The education community is reimagining and redesigning to build back better. Iyengar uses the principles behind UNESCO's Futures of Education initiative to highlight their importance in the post-COVID-19 recovery. The pandemic has shown how communities can come together to educate children, and Iyengar argues that, postCOVID-19, education systems should recognize community-driven support systems, use technology to overcome the digital divide in learning, and focus more on SDG Goal 4.7 and its links to climate crises.

Kate Moriarty writes that the COVID-19 pandemic is an emergency of an exceptional scale, with major impacts on education globally and with significant new challenges for education in existing humanitarian contexts. She reflects on the immediate challenges of continuing education in humanitarian contexts and on the experience of the Inter-agency Network for Education in Emergencies (INEE) as a network supporting collective action of Education in Emergencies (EiE) practitioners globally. Moriarty also looks at INEE's plans to support quality distance education and issues to consider on the reopening of schools. She concludes with some thoughts on the needs and risks for EiE for the longer term.

Michael Thomas and Cathy Rogers argue that the science of learning has two different responsibilities in the COVID-19 crisis: first, to offer guidance about how best to deal with the impact of the current situation, including lockdown and homeschooling; and, second, to consider bigger questions about what this large-scale educational experiment might mean for the future. They summarize the advice for parents about mental health and about becoming stand-in teachers. Then, taking the longer view, they consider not only the potential negative impact of the COVID-19 crisis in increasing inequality in education but also the potential positive impact of driving innovations in technology use for educating children.

Sir John Daniel, former UNESCO Assistant Director General for Education, believes that the COVID-19 pandemic poses a huge challenge to education systems and offers guidance to teachers, institutional heads, and officials on addressing the crisis. What preparations should institutions make in the short time available, and how do they address students' needs based on level and field of study? Reassuring students and parents is a vital element of institutional response. In ramping up capacity to teach remotely, schools and colleges should take advantage of asynchronous learning, which works best in digital formats. As well as the normal classroom subjects, teaching should include varied assignments and work that puts COVID-19 in a global and historical context. When constructing curricula, designing student assessment first helps teachers to focus. Sir John also suggests 
flexible ways to repair the damage to students' learning trajectories once the pandemic is over and gives a list of resources.

\section{References}

ILO [International Labor Organization] (2020, March 18). Almost 25 million jobs could be lost worldwide as a result of COVID-19, says ILO. Press release. Geneva: ILO. https://www.ilo.org/global/about-theilo/newsroom/news/WCMS_738742/lang--en/index.htm.

Judt, T. (2012, February 10). Revolutionaries (NYR Daily). New York Review of Books.

Oxfam (2020). Dignity not destitution. Briefing paper. Washington, DC: Oxfam America. https://www. oxfamamerica.org/explore/research-publications/dignity-not-destitution/.

UIS [UNESCO Institute for Statistics] (2017). More than one-half of children and adolescents are not learning worldwide. Fact sheet 46. Montreal: UIS. http://uis.unesco.org/sites/default/files/documents/ fs46-more-than-half-children-not-learning-en-2017.pdf.

UNESCO (2020). \#LearningNeverStops. COVID-19 education response. Paris: UNESCO. https://en.unesc o.org/covid19/educationresponse/globalcoalition.

World Economic Forum (2019, September 24). We're all in the same boat on the SDGs: Here's how we steer a course. https://www.weforum.org/agenda/2019/09/sdg-financing-sustainable-development-impact-summi t-sailing/.

Publisher's Note Springer Nature remains neutral with regard to jurisdictional claims in published maps and institutional affiliations. 